\title{
DISEÑO TEXTIL INTERCULTURAL: ALCANCES SOBRE UNA INTERVENCIÓN EN TERRITORIO MAPUCHE-WILLICHE
}

\author{
INTERCULTURAL TEXTILE DESIGN: OUTLINE FOR AN \\ INTERVENTION IN MAPUCHE-WILLICHE TERRITORY
}

\section{PATRICIA G. ZÚÑIGA*}

RESUMEN: El presente artículo expone los alcances de una intervención de diseño realizada en la localidad de Llahualco, Región de Los Lagos, Chile, a artesanas textiles con ascendencia mapuche-williche. En particular, busca tensionar el concepto de desarrollo, en función del contexto intercultural donde se sitúa, analizando la figura de la mujer en la transmisión de conocimiento heredado y sus nuevos escenarios de validación. Junto con lo anterior, expone cómo la asimilación de nuevas técnicas artesanales, sus apropiaciones y nuevos usos, va generando nuevas tradiciones textiles para los territorios multiculturales del sur de Chile. Se espera realizar una aproximación a los principios de integración cultural aplicables a procesos de diseño, que permitan prospectar el desafío de la interculturalidad en los territorios de la globalización.

Palabras clave: Multiculturalidad, interculturalidad, globalización, diseño textil.

Aвstract: This article demonstrates the scope of a design intervention carried out in Llahualco, Los Lagos Region, Chile, with textile artisans of Mapuche-Williche ancestry. In particular, it seeks to question the concept of development as a function of the intercultural context of the village, analyzing the role of women in the transmission of inherited knowledge and new scenarios for validation of that knowledge. Furthermore, the article demonstrates how the assimilation of new artisanal techniques, along with their appropriations and novel uses, is generating new textile traditions for the multicultural territories of southern Chile. This project offers an approach to the principles of cultural integration applicable to design processes, thus enabling us to explore the challenge of interculturality in territories open to globalization.

KEYwORDs: Multiculturalism, interculturality, globalization, textile design.

Recibido: 21.05.18. Aceptado: 24.10.19.

\footnotetext{
* Magíster en Educación y Multimedia. Académica Universidad Católica de Temuco, Temuco, Chile. Correo electrónico: pzuniga@uct.cl
} 


\section{INTRODUCCIÓN}

Z n los “infinitos rincones infinitos” (Sepúlveda, 2010, p. 95) del sur de Chile, encontramos enclavadas localidades rurales cuya identidad está vinculada a la tradición campesina y a la cultura ancestral mapuche, donde la colonización y, actualmente, la globalización han aplicado un proceso sostenido de asimilación cultural. Las prácticas y los usos tradicionales de la cultura material y la artesanía constituyen prácticas de resistencia al concepto de desarrollo impuesto por las culturas dominantes (Roldán, 2009).

En estos territorios, la recuperación de la identidad ha sido un fin promovido por distintas instituciones públicas relacionadas con la cultura y el desarrollo local. Sin embargo, esta idea de recuperación cultural, implícitamente da cuenta de cierta inmovilidad de las culturas y sus expresiones, situación que desfavorece la integración cultural. Avanzar hacia un proceso de interculturalidad implica el enfrentamiento de imaginarios que permiten un reconocimiento de los valores trascendentes de cada cultura y reconocer un "mestizaje" cultural que se manifiesta en apropiaciones y nuevos usos de conceptos y nuevas expresiones que conforman indisolublemente cada unidad cultural.

Para Ariño, la cultura "es el conjunto de procesos que desarrollan las potencialidades transformadoras del medio en que se (sic) viven los seres humanos" (citado en Conill, 2015, p. 78), y el arte, en particular el arte textil, constituye un elemento capaz de comunicar las visiones y concepciones culturales de los territorios rurales. Conill (2015) plantea que el concepto de cultura se ha ideado desde el universalismo ilustrado bajo las ideas de mejora humana y progreso, concibiendo lo humano desde una perspectiva abstracta y uniformadora. Frente a esta postura, han surgido otras tendencias que resaltan la diversidad cultural y sus diferentes modos de vida, que plantean que cada cultura posee una racionalidad propia que "serían inconmensurables y sus contenidos más propios intraducibles" (p. 78) y olvidan las distintas dinámicas que se han dado a lo largo de la historia, como los procesos de aculturación e hibridación, que dan cuenta de la inexistencia de culturas puras. Para el autor, la aculturación es "una forma de intercambio cultural que resulta del contacto directo y continuo entre grupos de culturas diferentes, que entrañan cambios culturales en las prácticas iniciales de uno o de los dos grupos, una reciprocidad de influencias" (p. 79). Existen tres posiciones para referirse a las relaciones entre culturas: la asimilación, la multiculturalidad y la interculturalidad. La primera es el proceso de acomodarse por completo a la cultura dominante; la segunda, 
presente en gran parte de los territorios actuales, que consiste en un cierto "mosaico cultural", que relega a las minorías y sus culturas a guetos. Y la tercera, la interculturalidad, es "un intercambio, un mestizaje, aún perdiendo señas de identidad, que puede acabar en una asimilación de unas culturas por otras, las más poderosas... pero al menos siempre como producto de una integración cultural de la pluriculturalidad y el pluralismo" (p. 80). También refuerza la idea anterior planteando que la integración cultural consiste en un mestizaje y que "los dinamismos de la integración mediante la comunicación y el intercambio fomentan el posible perfeccionamiento mutuo manteniendo las diferencias mediante procesos de aculturación" (p. $81)$.

Considerando lo anterior, en este trabajo lo multicultural significa la existencia de varias culturas en un mismo territorio, que permite vislumbrar las relaciones de integración cultural presentes en las expresiones textiles de los territorios mapuche-williche. Los saberes y prácticas tradicionales, junto a la incorporación y apropiación de nuevas técnicas y nuevas formas de representación, son manifestación de dicha integración producida por el intercambio cultural o mestizaje (Conill, 2015).

Inicialmente, se presenta el caso de dos distintas experiencias en territorio mapuche-williche del sur de Chile, Región de Los Lagos: uno, la intervención de diseño ejecutada en la localidad de Llahualco, comuna de Río Negro, y dos, los tapices textiles creados por artesanas de la comuna de Purranque, ambas localidades expuestas a procesos de colonización, que ha derivado en un mestizaje y la aculturalización de las zonas rurales del sur de Chile. Uno de sus efectos es la asimilación de costumbres, ideales, creencias, etc. de la cultura dominante, que va debilitando los elementos de su identidad (Macías, 2015, p. 96). No obstante, a través de procesos de reconocimiento de los elementos identitarios, la apropiación y la integración de técnicas y lenguajes textiles propios de la cultura dominante, las artesanas y el arte textil han generado discursos de resistencia y control cultural, que favorecen experiencias de diálogo intercultural, promovidas tanto por artistas y artesanas como por instituciones públicas relacionadas con la cultura. Es el caso de los tapices textiles realizados por Viviana Rantul en colaboración con la maestra Elba Cumian y el artista visual Eduardo Rapiman, cuyas obras expresan la identidad local a partir de un diálogo con el pasado y la ancestralidad mapuche, que dan cuenta de un proceso de apropiación cultural de técnicas y lenguajes textiles de la cultura hegemónica para la creación de textiles con identidad cultural mapuche. 
Finalmente, se expone un modelo de intervención desde el diseño, sus fundamentos y aportes, en búsqueda de favorecer la elaboración de un discurso cultural simétrico para las obras textiles tradicionales, que involucra tanto a actores del Estado como a actores territoriales para su ejecución.

\section{LA DIMENSIÓN TERRITORIAL DEL DISCURSO}

En las localidades rurales del sur de Chile, el Estado ha implementado estrategias de asimilación cultural con el pueblo mapuche, que por un tiempo renegó de costumbres ancestrales para asimilarse a la cultura dominante, adoptando formas de vida y tradiciones provenientes del mundo criollocampesino. Para Boccara y Seguel-Boccara (1999), este proceso de deslegitimización de "lo indígena" constituye un despojo cultural que, junto con la ocupación de los territorios, se consolidó a través de la institucionalidad estatal, y "la negación e invisibilización jurídica y socio-política de la diversidad cultural interna" (citado en López, Christian, Vargas, Calcagni y Fuentealba, 2016, p. 3). De esta manera, según Boccara (2009), se genera la "campesinización, pauperización, y minifundización de la propiedad indígena en las zonas rurales" (citado en López et al., 2016, p. 6), donde el Estado ha promovido una política pública de asimilación, que favorece el desarrollo positivista implantado por el neoliberalismo, excluyendo la participación de los pueblos indígenas, invisibilizando su cultura y negando su derecho a la autonomía (López et al., 2016). Desde la perspectiva cultural, este proceso de dominación determina la presencia de una multiculturalidad presente en estos territorios.

Llahualco ${ }^{1}$ y Purranque se ubican en la Cordillera de la Costa y pertenecen a las Grandes Tierras del Sur, conocidas como la Fütawillimapu y habitadas por el pueblo mapuche-williche. Dicho pueblo, según Bengoa (citado en Foerster y Vergara, 2001, p. 30), "posee una nostalgia con (sic) su pasado de abundancia” (p. 152), de un período anterior a la pacificación caracterizado por el esplendor ganadero, constituyendo un ideal donde "pasado y futuro se mezclan de manera natural" (Bengoa, 1999, pp. 78-80). Esto explicaría para Bengoa (1999), una de sus características más relevantes: el

\footnotetext{
${ }^{1}$ Llahualco en la toponimia mapuche corresponde al sonido y a la interpretación que el lugareño da cuando camina en zaguanes o pantanos: "es el ruido o sonido que produce el pie al enterrarse en el lodo". (Definición obtenida a través de entrevistas a habitantes del sector, realizadas por Rafael Andrade, docente y director del Liceo de Riachuelo, comuna de Río Negro, en comunicación personal, 2012).
} 
apego a la cultura tradicional, cuyo "discurso más profundo de la cultura mapuche es antimoderno" (citado en Foerster y Vergara, 2001, p. 30). Esta característica no excluye al arte textil, que para la tejedora mapuche es un acto creativo, "transformador" (Quilapi y Salas, 1999, p. 16) en esencia, que materializa la comprensión de la cosmogonía mapuche, a través de un acto manual y une el origen con el presente (Quilapi y Salas, 1999).

Estos territorios también poseen una historia híbrida, que para GarcíaCanclini (1989) es una característica de los países latinoamericanos y el resultado de la sedimentación, yuxtaposición y entrecruzamiento de las tradiciones indígenas, del hispanismo colonial católico y de las acciones políticas, educativas y comunicacionales modernas. Estos elementos son visibles en los tejidos de las artesanas de la localidad de Llahualco, que mantienen vigente la tradición mapuche-williche del telar y la cultura campesina criolla, caracterizada por el uso de técnicas de tejido a palillo y crochet en la creación de objetos utilitarios para la vestimenta e íconos propios de las creencias de la cultura hegemónica: la imagen de la Virgen y de la Iglesia Católica.

Si bien la utilización de íconos foráneos y la incorporación de técnicas criollas son producto de la asimilación cultural hispano-criolla, el reconocimiento histórico y el diálogo con el pasado de las artesanas textiles ha permitido el desarrollo de un proceso de "asimilación" (Macías, 2015, p. 98) de los lenguajes y técnicas que puede ser comprendido desde la perspectiva de Zea (1969, p. 9), como "hacer propio lo que parece extraño, acomodarlo a lo que se es, sin pretender por el contrario, acomodar el propio ser a lo que le es extraño" (citado en Macías, 2015, p. 98). Este proceso de reconocimiento histórico y cultural ocurre en algunas localidades como es el caso de Purranque, donde su historia textil ha constituido un elemento favorecedor de este proceso.

Otra característica del arte textil del sur de Chile es el rol social y cultural de la mujer. La tejedora tradicional mapuche cumple un papel de privilegio social, ya que su arte es parte de la estrategia de educación y transmisión de valores, religiosidad y mitos de su pueblo, y la oportunidad de hablar de la vida antigua. Para Martínez (2001), los telares para la cultura mapuche-williche "son y seguirán siendo un modo de expresión" donde la mujer recoge "la luz de su entorno, de su quehacer, de su vida interior y de su tradición" (p. 79).

Junto con lo anterior, hay que mencionar el uso del textil que realizan las instituciones públicas, con la ejecución de talleres de capacitación para mujeres, con el fin de profesionalizar el oficio como herramienta de supe- 
ración de la pobreza. Esto implica un reconocimiento a la tradición del textil de esta zona y de su potencial turístico y cultural. No obstante, dichas iniciativas se efectúan en lugares desprovistos de significación cultural, lo que despoja a la expresión de su sentido colectivo vinculado a los saberes tradicionales y la relega a una condición de oficio técnico. Esta invisibilización de los componentes culturales del textil determina una desvalorización de su uso comunitario y una pérdida del patrimonio. Es así como en estas localidades rurales la lucha por la subsistencia ha favorecido procesos de desarraigo, determinando la emigración de los jóvenes y la fractura de la tradición artesanal en mujeres jóvenes.

Paralelamente, surge la valoración del oficio artesanal por la institucionalidad y el concepto de artesano transita desde una visión de hacedor a una de creador que "elabora sus obras para que otras personas conozcan sus historias, sus sentimientos, y por el gusto que siente por su actividad artesanal" (Barrera, 2011, p. 183). Esto genera un proceso de conversión de la artesanía en bien de consumo, siendo los consumidores quienes otorgan valor a los productos artesanales en la medida en que satisfacen sus deseos de identidad, pertenencia y estatus, donde los conceptos de desarrollo, civilización y bienestar son reemplazados por los términos "modernidad, tecnología, participación y consumo" (Estermann, 2014, p. 356). Es el caso del programa Sello de Excelencia de la Unesco al cual Chile está adscrito, que busca reconocer los artesanos de excelencia y sus obras, y generar plataformas globales para la artesanía nacional.

\section{SOBRE LA EXPERIENCIA DE DISEÑO EN LA LOCALIDAD DE LLAHUALCO}

Tal como se expresó anteriormente, Llahualco es una localidad rural de ascendencia mapuche-williche, que ha sido sometida a procesos de asimilación cultural que han determinado una cultura fundamentalmente campesina con matices de su origen indígena. Con respecto al textil, estos procesos han favorecido la incorporación de elementos culturales propios de la cultura dominante y la comunicación de masas a las expresiones textiles, para posibilitar la obtención de un mayor beneficio económico, tan anhelado por las mujeres campesinas.

La intervención consideró el concepto de sustentabilidad como uno de los ejes centrales de la propuesta, ya que buscó favorecer el desarrollo a escala humana de los territorios. Elizalde (en López et al., p. 11) sostie- 
ne que la sustentabilidad tiene cuatro dimensiones: la política, la cultural, la económica y la social. La dimensión cultural se relaciona directamente con el enfoque de desarrollo territorial rural, que centra su accionar en la participación de los habitantes de la localidad en escenarios socio-políticos para el ejercicio de sus derechos, como un proyecto integrador y colectivo, construido desde la identidad de los pueblos y de las interrelaciones en el territorio multicultural.

Otro aspecto central es el sujeto. En este caso las artesanas son la clave para detonar en la comunidad un proceso de recuperación de la memoria en un escenario intercultural (López, 2015), favoreciendo la integración cultural basada en la participación de los habitantes como agentes de cambio, ya que son ellos quienes conocen las necesidades e intereses y poseen los conocimientos de sus comunidades para ejercer sus derechos en espacios de expresión política y social (López et al., 2016). Dicha integración se da inicialmente en el sujeto, que es quien reconoce al otro como un igual, identificando sus diferencias y semejanzas en la construcción de su vida personal. Para las culturas, es un proceso similar, las identidades se construyen en el intercambio con otras identidades territoriales que establecen un proceso relacional para desafiar al multiculturalismo, es decir, "aprehendemos las otras culturas como semejantes y, a la vez, como diversas" (López, 2015, p. 79). Esta relación recíproca implica que los sujetos interpelan sus propias creencias y su cultura para comprender su propia identidad. Es a través de la identidad y sus elementos icónicos que se establece el discurso textil, narrando el paisaje cultural, las vivencias y las experiencias de los individuos.

La experiencia buscó generar discursos de simetría que favorecieran el reconocimiento y el diálogo, con el fin de promover la integración cultural a través del arte textil. El proyecto "Mejoramiento de los productos textiles de las artesanas de Llahualco y transmisión de su saber a la comunidad: Talleres de diseño aplicados a la artesanía textil, para el mejoramiento e innovación de sus productos y valoración cultural del oficio textil en su comunidad", financiado por el Consejo Regional de la Cultura y las Artes, Región de Los Lagos (2012), nace del diálogo de distintos actores locales y regionales que vieron la oportunidad de generar un proyecto piloto, en el cual el desarrollo sustentable de las localidades rurales estaba ligado directamente a la valorización de las raíces de la cultura local y a la transmisión de su sabiduría a las nuevas generaciones. Si bien su objetivo general estaba orientado al mejoramiento de los productos artesanales utilizando el diseño como herramienta estratégica de desarrollo, la complejidad cultu- 
ral de las localidades y la pérdida de valor del patrimonio inmaterial local orientó la acción del diseño a indagar sobre estrategias que fomentaran la valoración de la identidad local de las propias comunidades, considerando el aprendizaje experiencial y la creación como ejes fundamentales de la intervención, para el desarrollo de "una experiencia históricamente singular, como la creación de un dominio del pensamiento, y de la acción" (Escobar, 1998, p. 31).

En este contexto, la intervención de diseño se focalizó en la creación de una estrategia de posicionamiento que aportara a la recuperación de referentes culturales locales. Desde esta perspectiva, se promovió la vinculación de las artesanas textiles con la comunidad escolar de la Escuela de Llahualco, con el fin de establecer canales de participación en espacios comunitarios legitimados por la cultura dominante para fortalecer la acción de la mujer como transmisora de los conocimientos tradicionales a las nuevas generaciones, aportando al aumento de su autoestima y al reconocimiento de su rol en el desarrollo social y cultural de su comunidad. Asimismo, en la promoción de un espacio de diálogo entre artesanas, escuela y sistema público: comunal, provincial y regional, vinculados a la educación y la cultura (Véase Fig. 1).

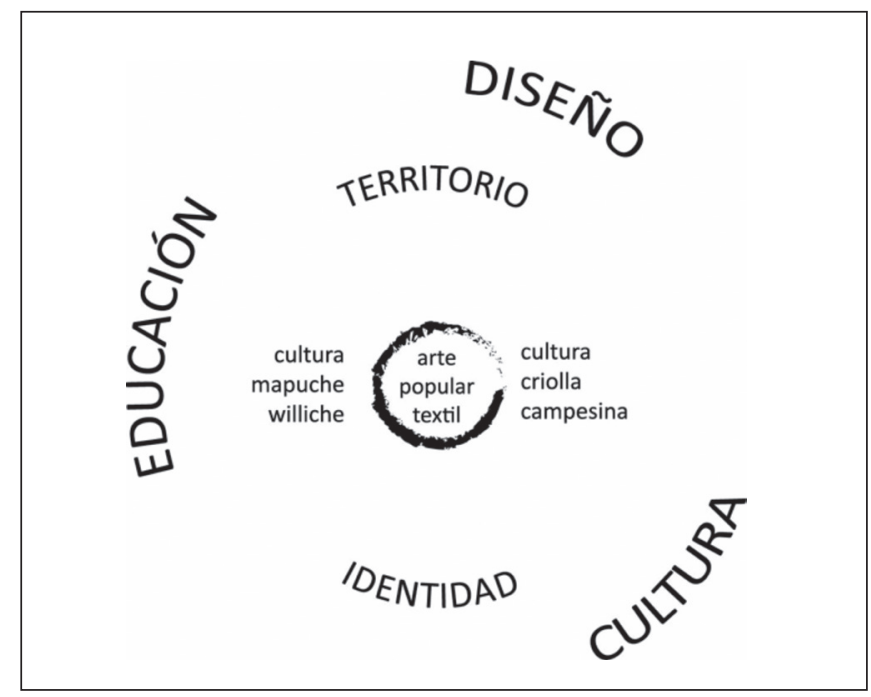

Figura 1. Esquema de trabajo inicial de intervención de diseño en contexto intercutural. 
Para la ejecución del proyecto se consideraron dos niveles de intervención. El primero, la significación del territorio y su identidad, caracterizada por la presencia de la cultura mapuche-williche y la campesina criolla, lo cual lo sitúa en un espacio de multiculturalidad. El segundo, las áreas fundamentales para la generación de acciones que buscaron incorporar distintos actores comunitarios y político-sociales que propiciaran un escenario de respeto y valoración de las expresiones artísticas locales, como lo es el arte textil. Se diagnosticaron los lugares de trabajo de cada una de las tejedoras de la agrupación con entrevistas en terreno y observación directa de los productos, con el fin de caracterizar sus tejidos desde una perspectiva cultural y productiva, utilizando fichas de documentación desarrolladas por el Área Artesanía del Consejo Nacional de la Cultura y las Artes (CNCA, 2008). Se evidenció en las artesanas un dominio de las técnicas ancestrales y criollas, y un retroceso en la apropiación del contexto cultural de la expresión, debido a la incorporación de referentes extranjeros en la creación de prendas textiles, con el objetivo de aumentar la venta y ampliar los escenarios de consumo de los tejidos. Sin embargo, las tejedoras con ascendencia williche-mapuche y/o tradición campesina, mantienen la producción artesanal tradicional. Dicha herencia cultural se manifiesta en la comprensión de las artesanas del valor del arte textil de las zonas rurales de la provincia y particularmente de su función simbólica, expresadas en el uso iconográfico y tintóreo, basado en conocimientos transmitidos de generación en generación sobre la naturaleza, el territorio y su cultura. Para la cultura mapuche, el arte textil se aprecia desde su "contexto cultural y en la cotidianidad de la vida mapuche" (Quilapi y Salas, 1999, p. 8) y constituye un acto ritual que permite la transmisión del mito y cuyo resultado, el tejido, "es una metáfora para entender lo cotidiano y lo sagrado, entre lo divino y lo terreno" (Quilapi y Salas, 1999, p. 39), mientras los conocimientos tradicionales son "la manifestación viva de las posibilidades que nos brinda el arte para crear un puente intercultural" (Quilapi y Salas, 1999, p. 8).

El proyecto contempló tres etapas: la primera, de observación y acercamiento al arte textil y el desarrollo de nuevos productos con la metodología de los referentes culturales para la valoración del entorno. Para Artesanías de Colombia (2008), esta metodología es un punto de partida para el diseño participativo entre artesanos y diseñadores, quienes trazan expectativas y estimulan el proceso de creación a través de la inspiración que proviene de las personas, emociones, lugares y formas que conmuevan al sujeto, utilizando estrategias de innovación que relacionan cultura, diseño y la industria artesanal en el desarrollo de productos. Desde la perspectiva cultural, 
busca rescatar la identidad territorial, las tradiciones y sus referentes; junto a técnicas ancestrales y tradicionales, la utilización de materias primas sostenibles y el mejoramiento tecnológico para la preservación de la memoria artesanal de los territorios. Es así como esta primera etapa estuvo dirigida a las artesanas y a la realización de talleres de diseño. Se partió de la base de que las artesanas son depositarias de saberes tradicionales, por lo tanto, se trabajó en torno a las representaciones que daban vida a los textiles, para plasmar el paisaje cultural cotidiano de la localidad. De esta manera los talleres de diseño no se centraron en la técnica ya aprendida y heredada, sino en un proceso de observación de su entorno cultural como una primera aproximación que permitiera develar el contenido cultural asimilado por las culturas dominantes. Lo anterior implicó definir y evaluar conjuntamente aspectos de diseño, calidad y formas de exhibición de los textiles para audiencias comunales, provinciales y regionales vinculadas al arte y la cultura, y los agentes culturales involucrados en el desarrollo de la iniciativa.

La segunda etapa fue de trabajo en aula en la escuela local unidocente. Se desarrollaron talleres vivenciales para la realización de proyectos individuales, con el fin de crear obras textiles que rescataran los paisajes y cuentos de la localidad. Participaron 10 estudiantes con ascendencia mapuche-williche de niveles de primero a séptimo de enseñanza general básica. Dado el objetivo de recuperar y validar el arte textil como una herramienta cultural, se consideraron para esta etapa tres hitos fundamentales: primero, la participación del lonko Anselmo Antilef ${ }^{2}$ en el aula, para generar un vínculo entre pasado y presente, y la comprensión cultural del territorio. Su intervención interpeló a los estudiantes a reflexionar sobre su pertenencia a la cultura ancestral pasando por sobre sus prejuicios producidos por la asimilación cultural y el desarraigo territorial. Segundo, la participación del docente y autoridad educativa de la comuna, quien introdujo a los estudiantes en el tema a través de un relato literario y una reflexión que culminó con una interpretación artística personal plasmadas en dibujos. Estos luego fueron tejidos en un tapiz mural con la colaboración en el aula de las artesanas textiles de la localidad. Si bien este método es utilizado por dis-

\footnotetext{
${ }^{2}$ El pueblo mapuche-williche, a diferencia de los mapuches de la Araucanía, conserva sus autoridades tradicionales, los caciques o lonkos, cuyo rol histórico ha determinado la persistencia de dicho pueblo frente a la asimilación cultural promovida por el estado chileno. Gracias a ellos, el proceso de desplazamiento y ocupación territorial llevado a cabo desde el siglo XIX no terminó en una "limpieza étnica", constituyendo uno de los factores relevantes para la vigencia de la autoridad del cacique o lonko (Foerster y Vergara, 2001, p. 32).
} 
tintos establecimientos con ascendencia mapuche de la región, la diferencia radicó en la pertenencia de las artesanas a la comunidad, lo que otorgó significación a la experiencia del sujeto, y a la recuperación y valoración del rol de transmisión de tradiciones de las mujeres y artesanas textiles mapuche-williche. Tercero, la participación de estudiantes, docentes, artesanas y autoridades territoriales, comunales y regionales de la educación y la cultura en la inauguración de la exposición de obras de estudiantes y artesanas en Universidad local (Ver Fig. 2). Esta acción permitió generar un diálogo intercultural y generacional en búsqueda de una comprensión y validación tanto del arte textil como de las artesanas de la localidad de Llahualco como agentes culturales de su comunidad y transmisoras de la herencia cultural.

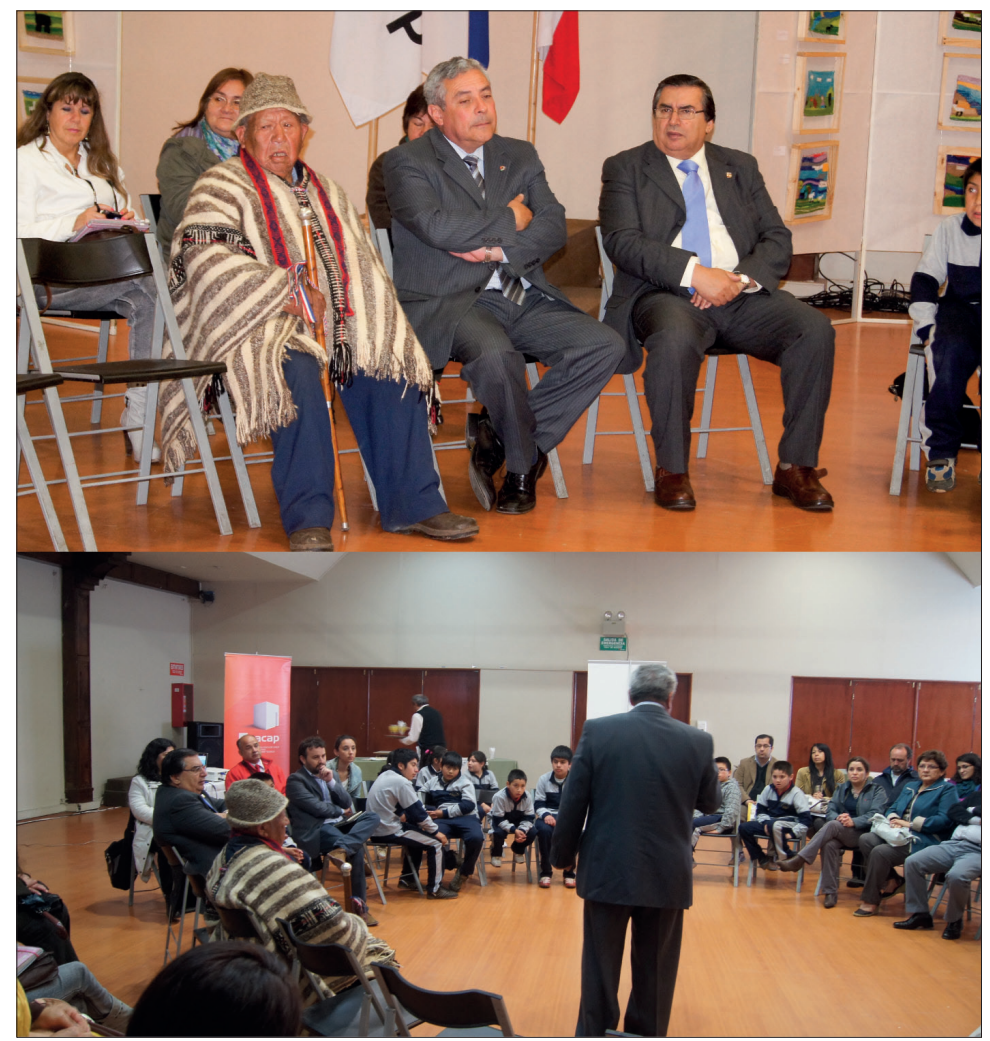

Figura 2. Experiencia de integración en la inauguración de la exposición textil "Tejiendo Sueños de Llahualco", con la presencia de las tejedoras, los estudiantres y docente de la escuela rural, el lonko don Anselmo Antilef, el Alcade y el director de la DAEM Río Negro, junto a autoridades del Consejo Regional de Cultura Los Lagos. 
La tercera etapa estuvo orientada a la visibilización de las obras en espacios culturalmente validados, de tal manera de favorecer la construcción de un puente entre arte y artesanía que permitiera el reconocimiento de las obras de estudiantes y artesanas, y la valoración del arte textil de la localidad como patrimonio inmaterial de la comunidad rural. Para ello, y con el fin de desarrollar la imagen de marca de la agrupación, se estableció un programa de diseño participativo. Así, se definió el nombre de fantasía "Tejiendo sueños de Llahualco", para reflejar las esperanzas vinculadas al territorio y sus familias. También se diseñó equipamiento apropiado para la exposición de las obras en galerías universitarias y centros culturales, y el material de difusión contempló un discurso orientado a la visibilización de las artesanas, el territorio y la tradición textil de la localidad, que buscó recuperar la nominación de arte textil incorporando características de las obras de arte de la cultura dominante a los textiles: soportes, lugares y modos de exhibición (Ver Fig. 3).

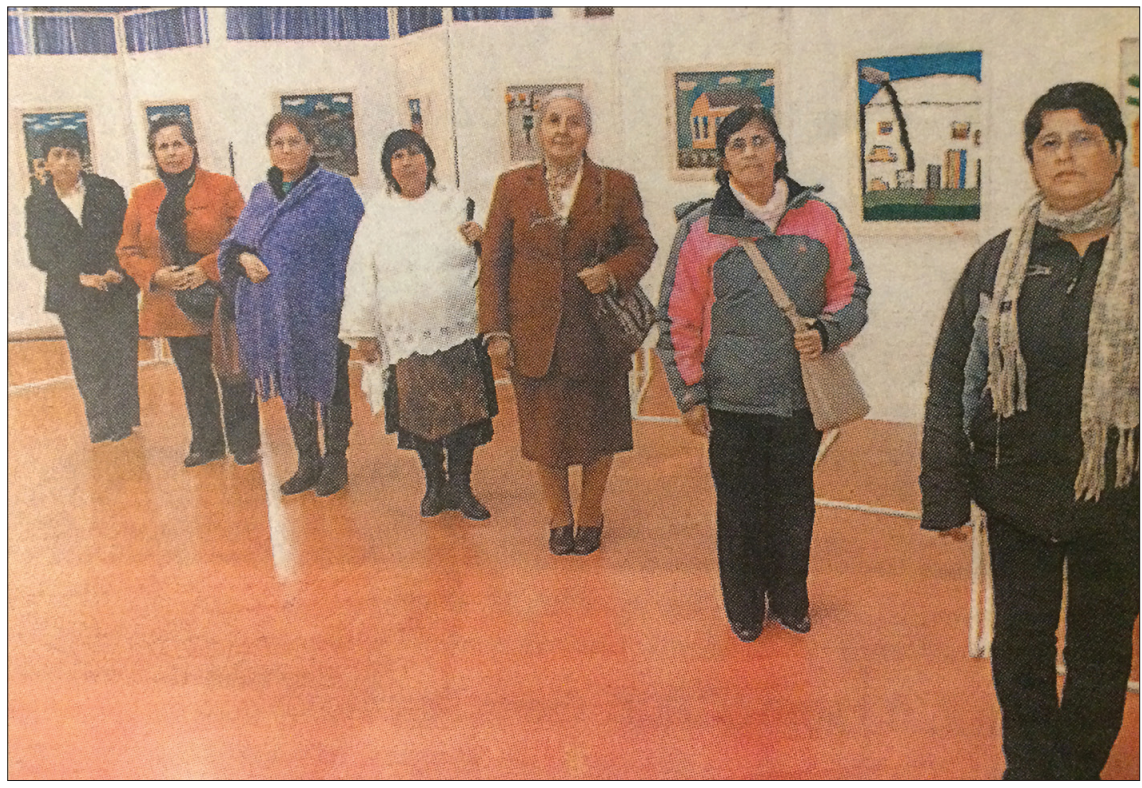

Figura 3. Artesanas textiles y sus obras en inauguración de la exposición textil “Tejiendo Sueños de Llahualco”. Fuente: Diario Austral de Osorno, 6 de diciembre 2012.

El proceso estuvo teñido de un diálogo reflexivo sobre el papel de la mujer en la cultura, sus sueños y deseos de participación activa en la comu- 
nidad y sus ansias de una vida mejor. Es en este espacio colaborativo donde ellas recuperan su rol cultural de transmisoras de conocimientos y agentes de cambio, donde su acción une el pasado y el presente aportando al desarrollo humano y sustentable de sus territorios.

Finalmente, la intervención logró establecer puentes para la discusión en espacios de simetría cultural, donde las autoridades territoriales y del Estado participaron en un espacio de integración cultural (Conill, 2015), junto a niños, artesanas y obras textiles, logrando establecer una comunicación e intercambio de su subjetividad, que da cuenta de un "mestizaje" basado en el pluralismo cultural y que se observa en las obras textiles.

Esta recuperación ocurre en un proceso de "mestizaje" (Conill, 2015, p. 80) característico de los territorios rurales indígenas sometidos a la colonización chilena, que en el escenario de la artesanía textil permite que las técnicas artesanales asimiladas sean utilizadas en un proceso de apropiación cultural y significadas desde su uso por la comunidad, situación que implicaría un estado de integración cultural.

\section{SOBRE LA INVENCIÓN CULTURAL TEXTIL}

Anteriormente, planteamos que la apropiación y valoración de la artesanía ocurre principalmente en escenarios de consumo que son ajenos al territorio, determinando nuevas creaciones y usos para la artesanía textil; una de ellas el tapiz mural.

Podemos señalar que los cambios culturales del arte textil mapuche en los territorios de la Fütawillimapu han surgido a partir del "mestizaje" (Conill, 2015, p. 80) y sus nuevos usos han permitido la resignificación cultural de la expresión. En el caso de Llahualco, son las artesanas y estudiantes las que recrean el paisaje cultural de su entorno próximo, validando su forma de vivir, sus objetos y sus historias, para crear iconografía representativa a través de técnicas foráneas, como la del tapiz mural.

Para su creación, las artesanas utilizan la técnica denominada "telar de trama discontinua" ${ }^{3}$, incorporada al territorio mapuche-williche de $\mathrm{Pu}$ rranque por Cema Chile en 1980. Actualmente, es difundida por instituciones públicas, como el Servicio Nacional de la Mujer, como un oficio para

\footnotetext{
${ }^{3}$ Telar de origen Tiwanaku, que se caracteriza por ser rectangular y vertical, en él se disponen urdimbres a una distancia aproximada de $5 \mathrm{~mm}$ y a través de ellas, se teje la trama. Su particularidad es su versatilidad, que permite realizar representaciones naturalistas y abstractas. (V. C. Rantul, comunicación personal, 2016)
} 
mujeres rurales, y por la Educación Municipal como taller práctico para niños rurales y urbanos de las zonas de Osorno, Purranque y Río Negro.

En el caso de Purranque, el tapiz mural adquiere una significación distinta bajo la mirada de la maestra Elba Cumian ${ }^{4}$ y de Viviana Rantul ${ }^{5}$. Su obra textil y la de su grupo de mujeres tejedoras ha sido reconocida por las instituciones comunales, regionales y nacionales por su valor y tradición cultural artesanal (Ver Fig. 4) e incluye el rescate paisajístico e histórico de la comuna, relevando en él la cultura campesina criolla y su historia en imágenes textiles, como parte de su apego a la "situación de abundancia” planteada por Bengoa (1999, pp. 78-80). Es importante señalar que las obras están creadas bajo conceptos culturales mapuche; el uso del color no es utilizado solamente desde una perspectiva compositiva, sino también desde la perspectiva simbólica, reflejada a partir de un conocimiento extenso de las plantas tintóreas y pigmentos naturales del bosque nativo de la zona, representando la relación con la naturaleza.

Otra obra textil destacada es la realizada por Viviana Rantul para la Universidad Autónoma de Chile, sede Temuco, trabajo colectivo con el artista visual Eduardo Rapiman, que representa el concepto de dualidad presente en la cosmogonía mapuche, visualizado a través de lo femenino y lo masculino, que está encarnado en los dos artistas: textil y visual; hombre y mujer. Los tapices de gran formato, cada uno de 2 x 2,5 m están expuestos desde abril del año 2017 (Ver Fig. 5). Este caso constituye un ejemplo más de la función del telar en la cultura mapuche, articulada a partir de un proyecto colectivo arraigado a su origen cultural e inserto en un territorio multicultural y que se extiende a nuevos horizontes territoriales.

\footnotetext{
${ }^{4}$ Elba Cumian, maestra artesana de telar mapuche y trama discontinua, dictó clases en la Escuela Regional de Artesanos de Purranque desde sus inicios hasta su cierre. Desde entonces ha transmitido sus conocimientos a mujeres del sur de Chile, relevando el paisaje cultural de su territorio en tapices de pequeño y gran formato, por lo que ha obtenido reconocimientos del municipio por su aporte a la cultura de la comuna y la región.

${ }^{5}$ Viviana Rantul Bahamonde, discípula de la maestra lamuen Elba Cumian Soto, de quien ha aprendido la técnica de tejer telares, tanto en la técnica de trama discontinua como en el telar de pedales. Con la maestra Cumian han realizado dos exposiciones y ha sido capacitada y autorizada por ella para ejercer como tallerista para programas del Consejo de la Cultura en la Región de Los Ríos, Municipalidades de la región y también de manera particular.
} 


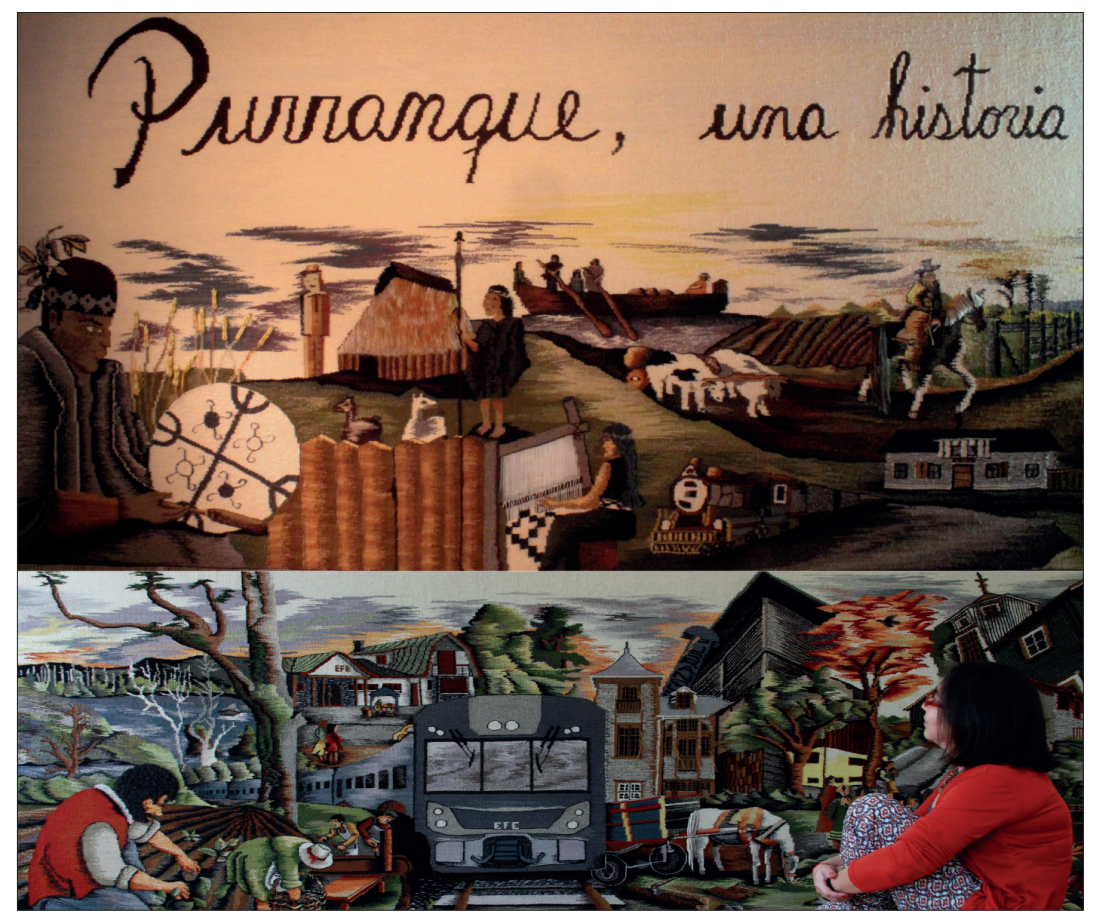

Figura 4. Obra textil "Purranque una historia contada en telar Parte 1 y 2" (20132014). Viviana Rantul y Elba Cumian. Más información: https://www.youtube. com/watch?v=ehRks7aLxJk. Fuente: Fotografía cedida por Viviana Rantul.

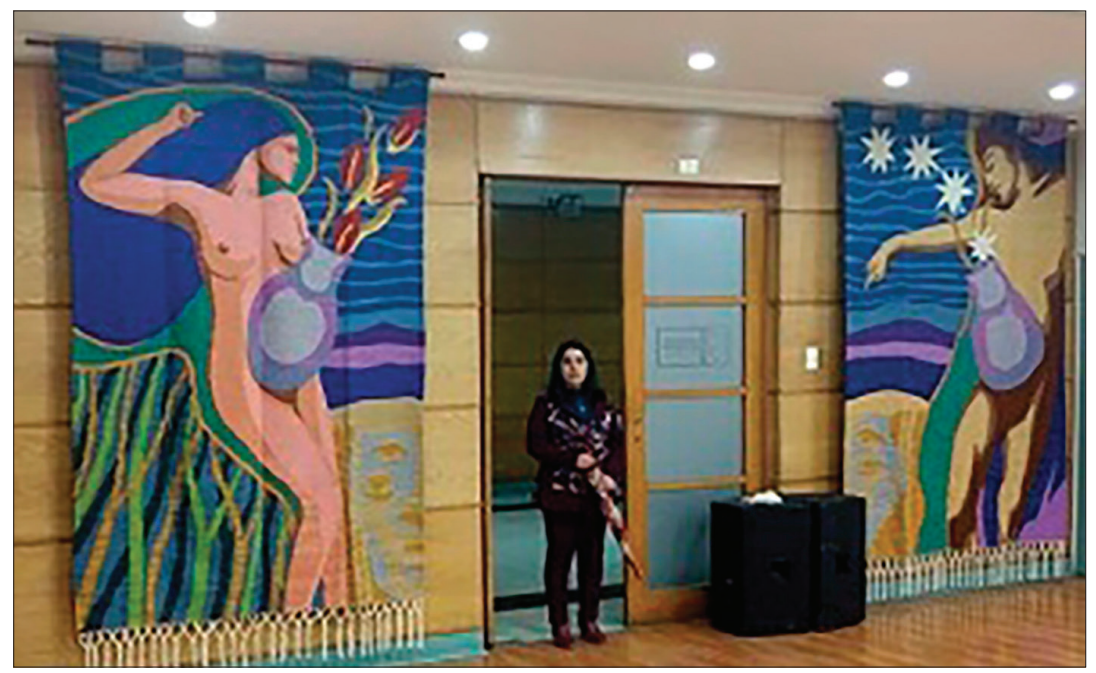

Figura 5. Obra textil "Dualidad"(2016). Viviana Rantul y Eduardo Rapiman. Fuente: Fotografía cedida por Viviana Rantul. 
El uso del tapiz mural resignifica los sueños de las artesanas textiles y da sentido, histórico y cultural, a las escenas tejidas, dando cuenta de la multiculturalidad del territorio mapuche-williche de la Fütawillimapu. Sin embargo, tanto la técnica como la iconografía, más bien naturalista, es ajena al arte textil mapuche. No obstante, es aquí, en el territorio multicultural, donde las artesanas textiles asignan un sentido a las técnicas no tradicionales. Este mestizaje, basado en la apropiación y uso de la técnica, determina que las artesanas la hereden como tradición, como una herramienta de expresión para la creación textil y transmisible a otras artesanas, para la representación de su paisaje cultural.

Si bien la técnica de telar discontinuo difiere del uso del telar mapuche y su simbología icónica, existen características culturales que se mantienen arraigadas a las prácticas artesanales tradicionales de la cultura mapuche. Una de ellas es el rol de la mujer en la transferencia de conocimiento a las propias artesanas y a la comunidad; es la mujer mapuche la encargada, a través de la urdimbre y el tejido, la llamada a preservar la tradición. Así también es ella quien transmite dicho conocimiento y aprendizaje a las nuevas generaciones. El tejido es y será una forma de comunicar las enseñanzas del pasado (Quilapi y Salas, 1999) y, en el territorio multicultural, la cotidianidad del presente y el sueño del futuro.

Es así como la mujer mapuche seguirá cumpliendo su rol educativo y cultural para la preservación de su cultura, a través del tejido de paisajes y representaciones figurativas y abstractas de contenido cultural, que generan nuevos discursos de integración en un territorio multicultural. Justamente, el valor que otorgan las mujeres artesanas a la técnica es que les da la posibilidad de representar el paisaje cultural desde una mirada figurativa y colectiva, capaz de ser transferida a nuevas generaciones que poseen distintos códigos de comunicación.

No obstante, dicha transmisión ocurre en escenarios de valoración ajenos a la tradición históricamente ocurrida en el núcleo familiar. En el caso de las obras de la maestra Elba Cumian y Viviana Rantul, en instituciones municipales y privadas; en el caso de Llahualco, en escuelas locales, donde las tejedoras se instalan como agentes culturales y transmiten su conocimiento dentro del marco curricular en espacios culturalmente validados para la transmisión del conocimiento occidental. Esta acción implica un reconocimiento de parte de la institucionalidad de los saberes tradicionales, un mecanismo de validación del textil en la comunidad escolar y, en definitiva, de la localidad (López et al., 2016). En dicho espacio se encuentran abuelas, madres, nietos e hijos en un proceso de validación y recuperación 
del arte textil, que cobra sentido cuando es parte de un proyecto colectivo arraigado al territorio. La escuela es un espacio de intercambio cultural, que permite la convergencia de distintos actores que tejen relaciones con el entorno cultural y territorial. La presencia del lonko y las tejedoras en el aula actúa como detonante de un proceso inicial de recuperación y diálogo intercultural visibilizado en los tejidos de niños y artesanas, que conforman una comunidad que se resiste al dominio cultural del poder hegemónico. Es así como se generan nuevos discursos textiles sobre un territorio hasta entonces despojado de un proyecto colectivo (Véase Fig. 6).

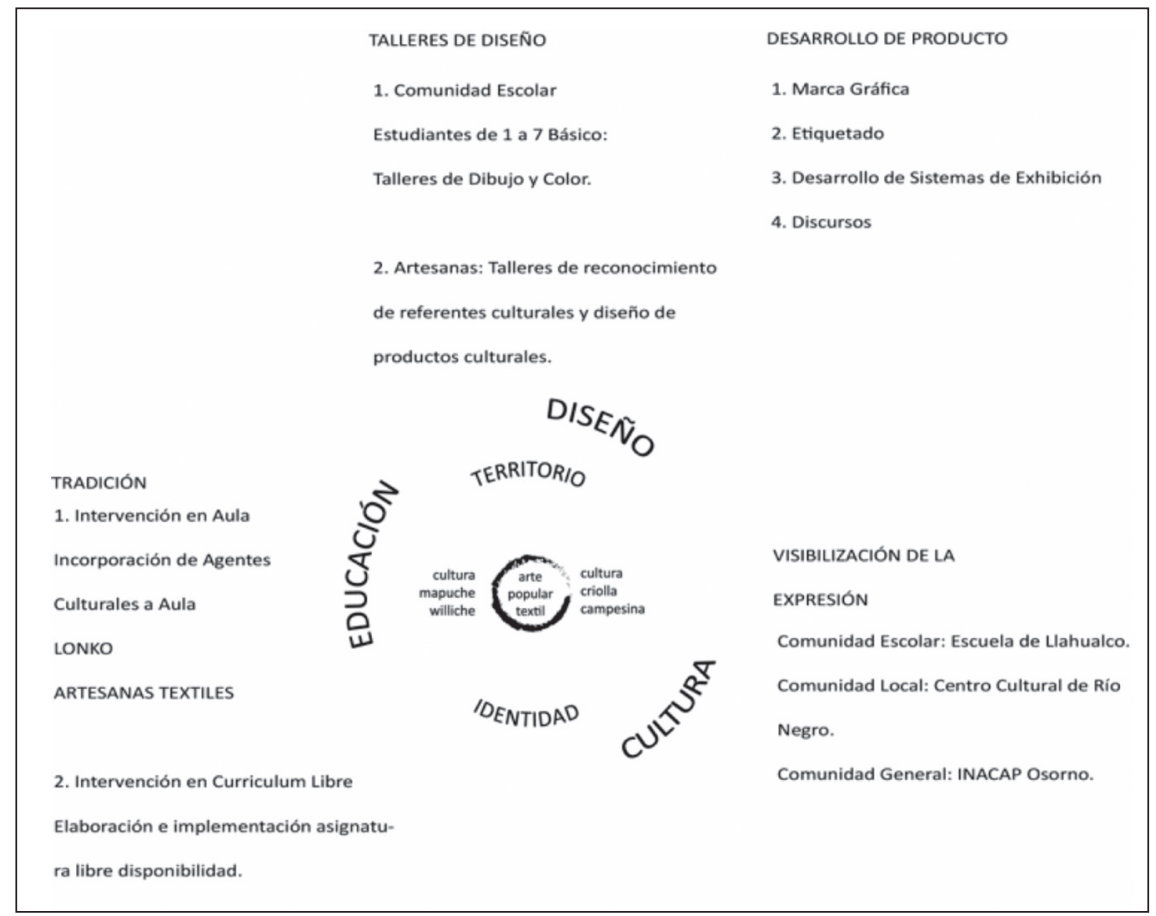

Figura 6. Modelo de intervención de diseño en contexto intercultural.

La visibilización y exhibición de las obras textiles en espacios universitarios, símbolos del conocimiento de la cultura dominante, permite la validación del arte textil de la comunidad de Llahualco y el reencuentro de 
cada uno de los participantes del proyecto, incluyendo a las autoridades territoriales y estatales en un espacio de simetría de poder y en una visión comunitaria del territorio, posibilitando la validez y resignificación del patrimonio cultural presente en el arte textil de nuestras localidades rurales del sur de Chile (Véase Fig. 7).

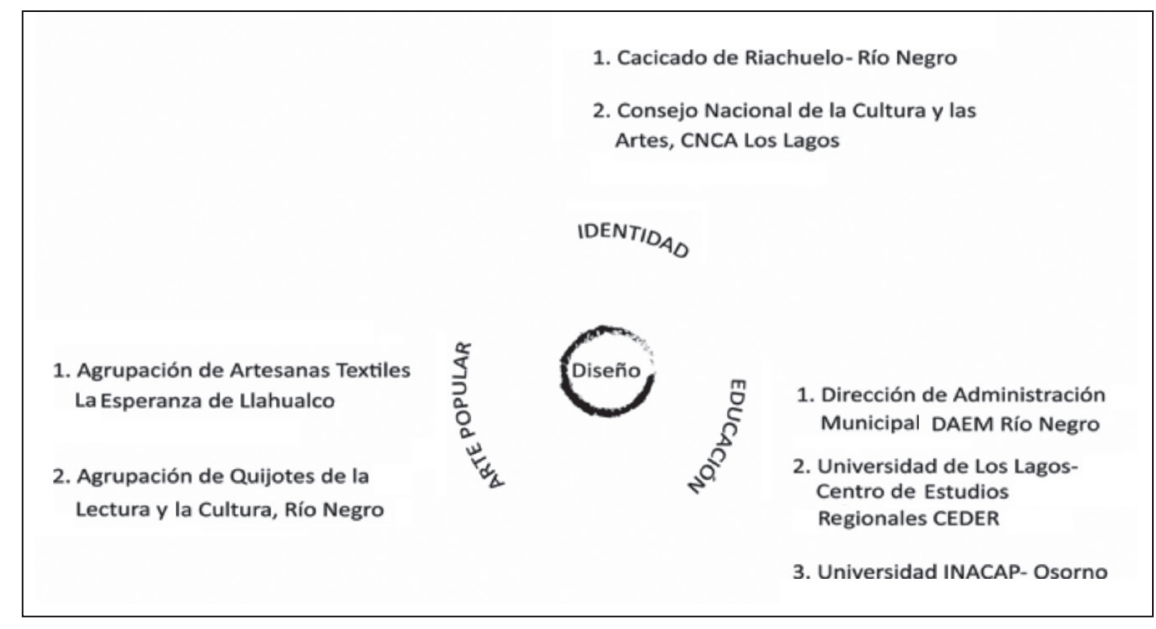

Figura 7. Actores relevantes en la intervención de diseño en contexto intercultural.

Dentro de este proceso, el diseño actuó mediando entre las distintas áreas y actores territoriales para posibilitar una mirada holística del problema. Esta mirada, que para el diseño contempla un proceso de innovación, implica la importancia de considerar su intervención bajo el enfoque de desarrollo territorial rural y sus dimensiones sociopolíticas y culturales que incorporen el sentido de lo humano, a través del diálogo intercultural y la participación activa de los sujetos en la construcción de las identidades territoriales y sus interrelaciones.

De esta manera, la innovación "es el resultado de procesos iterativos y de cooperación que se dan entre los diversos actores que intervienen en el proceso de generación y uso del conocimiento" (Chaparro, 2001, p. 29) y del diálogo intercultural que favorece el desarrollo sostenible de los territorios rurales, en particular, los arraigados a las culturas indígenas con tradición campesina. 


\section{CONCLUSIONES}

Las identidades territoriales cambian generando estrategias de invención y resistencia cultural en territorios de dominación, que resignifican la cultura dentro de los marcos de su cosmovisión en un territorio caracterizado por la multiculturalidad. Sin embargo, la tradición se basa en la comunicación e interpelación de culturas y es el resultado de un proceso de transmisión de ideas, formas de actuar y transferir lo aprendido y modelada por los individuos, quienes otorgan nuevas significaciones para la configuración de nuevas tradiciones. El arte textil y en particular el tapiz mural es un discurso intercultural, que favorece la integración en escenarios de multiculturalidad, proponiendo nuevos usos del arte textil en nuevos contextos culturales.

El diálogo intercultural se produce en escenarios de integración e intercambio, ya que no solo es la construcción del sujeto lo que la determina, sino también el contexto sociocultural donde "lo importante no es la identidad acabada, sino el proceso relacional por el que atraviesa” (López, 2015, p. 73). En consideración a lo anterior, las intervenciones de diseño deben propiciar la participación de distintos actores socioculturales e incorporar elementos de la identidad del contexto, estableciendo un proceso de comunicación relacional que permita la creación de un discurso simétrico de la tradición textil y sus sentidos. Este diseño comprende un proceso participativo que considera tres elementos centrales para la elaboración de un discurso integrador: la apropiación del sujeto de los elementos culturales exógenos, que a través de la obra interpelan a la cultura dominante, y significan y dan sentido a nuevas técnicas y nuevas formas de representación de su cultura; la tradición, que considera el rol tradicional de los agentes culturales del territorio y la participación de autoridades político-culturales del territorio y el Estado; y, finalmente, el desarrollo de un proyecto comunitario, que favorece nuevos usos de las obras textiles en nuevos contextos, para nuevas audiencias en escenarios de integración cultural. En este sentido, la intervención de diseño busca levantar un diálogo intercultural, proponiendo estrategias discursivas en distintos niveles, relacionando distintos relatos o narrativas: de los sujetos, de la comunidad, de las autoridades, de los nuevos territorios...

Es así como el diseño debe aportar a generar herramientas de mediación que apoyen un proceso de diálogo intercultural, que posibilite la opción de intervención preservando y comunicando el arte textil como una herramienta comunitaria de desarrollo. De la misma manera, la observación y 
conocimiento de los distintos discursos presentes en las identidades territoriales y las localidades rurales indígenas, sus características y representaciones, aporta a establecer estrategias que incorporan al sujeto en la construcción de las metas y discursos sociales, y cuya participación en espacios institucionalizados fomenta la construcción del diálogo y favorece la integración cultural (Salas, 2016). Esta observación relacional del entorno y la generación de espacios de reconocimiento permitirá avanzar en términos de la elaboración de estrategias de diseño que fomenten la interculturalidad crítica y no sean una acción más integrada al discurso hegemónico.

Es obligación del diseñador saber leer y proponer las posibles soluciones en un marco de humanismo y valores fundamentales, que aporte al desarrollo sustentable y al diálogo intercultural de nuestros territorios. Más aún en el proceso actual de migración impulsado por la globalización, que impone desafíos para las culturas y su interrelación, donde la interculturalidad es un valor esperable y la comunicación una herramienta de desarrollo humano.

\section{REFERENCIAS}

Álvarez, P. y Forno, A (eds.). (2001), Fütawillimapu. Osorno, Chile: CONADI. Artesanías de Colombia. (2008). Metodología de diseño por referentes. Documento en línea disponible en http://www.artesaniasdecolombia.com. co:8080/Documentos/Contenido/11306_metodologia-de-diseno-por-referentes.pdf, consultado 13.09.17.

Barrera, G. (2011). Campos de poder artesanales en la comunidad Kamsá de Sibundoy, Putumayo, Colombia. Del trueque a las tendencias de moda. Apuntes, 24(2), 178-195.

Bengoa, J. (1999). Historia de un conflicto. El Estado y los mapuche en el siglo $X X$. Santiago, Chile: Planeta.

Boccara, G. (2009). Los vencedores: historia del pueblo mapuche en la época colonial. $2^{a}$ edición. Santiago, Chile: Ocho Libros Editores.

Boccara, G. y Seguel-Boccara, I. (1999). Políticas indígenas en Chile (siglos XIX y XX) de la asimilación al pluralismo (el caso mapuche). Revista de Indias, $\operatorname{LIX}(217), 741-774$.

Conill, J. (2015). La interculturalidad en diálogo con la neurofilosofía práctica. THÉMATA. Revista de Filosofía, [S.1.], 52, 77-92.

Chaparro, F. (2001). Conocimiento, aprendizaje y capital social como motor de desarrollo". Ciência da Informação, 30(1), 19-31. Artículo en línea disponible en https://dx.doi.org/10.1590/S0100-19652001000100004, 16 de junio 2017.

Elizalde, A. (2003). Desde el Desarrollo Sustentable hacia sociedades sustenta- 
bles. Polis [En línea], 4. Artículo en línea disponible en http://polis.revues. org/7154, 30 septiembre de 2017.

Escobar, A. (1998). La invención del tercer mundo. Ciudad de México, México: Fondo de Cultura Económica.

Estermann, J. (2014). Colonialidad, descolonización e interculturalidad. Apuntes desde la Filosofía Intercultural. Polis, 13(38), 347-368. https://dx.doi. org/10.4067/S0718-65682014000200016

Foerster, R. y Vergara, J. (2001). Hasta cuando el mundo sea... los caciques huilliches del siglo XX, en P. Álvarez y A. Forno (eds.), Fütawillimapu (pp. 29-65). Osorno, Chile: CONADI.

García Canclini, N. (1989). Culturas Híbridas. Estrategias para entrar y salir de la modernidad. Ciudad de México, México: Editorial Grijalbo.

López, D.; Christian, C.; Vargas, M.; Calcagni, M.; Fuentealba, R. (2016). Desigualdad, y Territorio en los pueblos indígenas en Chile: un diagnóstico latinoamericano y propuestas de investigación desde Rimisp, serie Documentos de trabajo $\mathrm{N}^{\circ}$ 206, Grupo de Trabajo Desarrollo con Cohesión Territorial, Programa Cohesión Territorial para el Desarrollo. Rimisp, Santiago, Chile.

López, M. C. (2015). Diálogo intercultural ¿Una utopía del siglo XXI? Pensamiento. Revista de Investigación e Información Filosófica, [S.l.], 71(265), 73-94. ISSN 2386-5822. Artículo en línea disponible en: http://revistas. upcomillas.es/index.php/pensamiento/article/view/5412. doi:http://dx.doi. org/10.14422/pen.v71.i265.y2015.004.

Macías, K. (2015). El neocolonialismo en nuestros días. La perspectiva de Leopoldo Zea. Universitaes Philosophica, 32(65) [fecha de consulta 1 de abril de 2019]. ISSN 0120-5323. Disponible en: http://www.redalyc.org/articulo.oa?id=409543046004

Martínez, A. (2001). El lenguaje de la luz del sur. En P. Álvarez y A. Forno (eds.), Fütawillimapu (pp. 75-81). Osorno, Chile: CONADI.

Quilapi, A. y E. Salas (1999). Witral tradicional de Arauko. Cañete, Chile: Kallfun Museo.

Roldán, A. (2009). Prácticas comunitarias del desarrollo: una mirada desde los oficios y el trabajo. Polis, 8(24), 341-355. Artículo en línea disponible en https://dx.doi.org/10.4067/S0718-65682009000300016, 20 de diciembre 2016.

Salas, R. (2016). Teorías contemporáneas del reconocimiento. Atenea, 514, 79 93. https://dx.doi.org/10.4067/S0718-04622016000200079

Sepúlveda, F. (2010). Patrimonio, identidad, tradición y creatividad. Santiago, Chile: Ediciones de la Dirección de Bibliotecas, Archivos y Museos.

Zea, L. (1969). La filosofía americana como filosofía sin más. Ciudad de México, México: Siglo XXI Editores. 